\title{
Reproductive characteristics of the African pygmy hedgehog, Atelerix albiventris
}

\author{
J. M. Bedford ${ }^{1}$, O. B. Mock², S. K. Nagdas', , V. P. Winfrey ${ }^{3}$ and G. E. Olson ${ }^{3}$ \\ ${ }^{1}$ Departments of Obstetrics and Gynecology and Cell Biology and Anatomy, Weill Medical College of Cornell University, New York, \\ NY 10021, USA; ${ }^{2}$ Department of Anatomy, Kirksville College of Osteopathic Medicine, Kirksville, MO 63501, USA; and \\ ${ }^{3}$ Department of Cell Biology, Vanderbilt University, Nashville, TN 37232, USA
}

\begin{abstract}
To obtain further perspective on reproduction and particularly gamete function among so-called primitive mammals presently grouped in the Order Insectivora, we have examined the African hedgehog, Atelerix albiventris, in light of unusual features reported in shrews and moles. Atelerix proves to share many but not all of the characteristics seen in these other insectivores. The penis of Atelerix has a 'snail-like' form, but lacks the surface spines common in insectivores and a number of other mammals. Hedgehog spermatozoa display an eccentric insertion of the tail on the sperm head, and they manifest the barbs on the perforatorium that, in shrews, probably effect the initial binding of the sperm head to the zona pellucida. As a possible correlate, the structural matrix of the hedgehog acrosome comprises only two main components, as judged by immunoblotting, rather than the complex of peptides seen in the matrix of some higher mammals. The Fallopian tube of Atelerix is relatively simple; it displays only minor differences in width and in the arborized epithelium between the isthmus and ampulla, and shows no evidence of the unusual sperm crypts that characterize the isthmus or ampulla, depending on the species, in shrews and moles. In common with other insectivores, Atelerix appears to be an induced ovulator, as judged by the ovulation of some $6-8$ eggs by about $23 \mathrm{~h}$ after injection of hCG. The dense cumulus oophorus appeared to have little matrix, in keeping with the modest dimensions of the tubal ampulla and, while it was not quite as discrete as that of soricids, it did show the same insensitivity to $0.5 \%(\mathrm{w} / \mathrm{v})$ ovine or bovine hyaluronidase.
\end{abstract}

\section{Introduction}

The order Insectivora comprises several families that include shrews, moles, hedgehogs, solenodons, tenrecs and golden moles. Taxonomically and phylogenetically, the Insectivora continues to be the least stable mammalian group, as exemplified by a recent move to bring tenrecs and golden moles within an 'African' clade together with hyrax, elephant shrews and the aardvark (Springer et al., 1997; Stanhope et al., 1998). Nonetheless, because insectivores display some characteristics found in their eutherian progenitors, they are of interest as a possible route to a better understanding of certain aspects of mammalian evolution. Insectivores possess certain major novel features in both the male and female reproductive systems the functional significance of which are not yet understood, and which, it is clear, appeared only during the evolution of therian mammals (for review, see Bedford, 1991).

As yet, little work has been done on the reproductive tracts and gametes of most insectivores. An initial examination of various reproductive traits in the shrew,

Received 15 February 2000.
Suncus murinus, generated more questions than answers about reproduction in these animals (Bedford et al., 1994), and similar work has confirmed the general existence of unusual features, and also some diversity of gamete behaviour among different members of the shrew family. For example, it has been difficult to detect the changes seen in most mammals in the cell surface glycoproteins of spermatozoa as they pass through the epididymis. In addition, the shrew perforatorium and sometimes the acrosome display unusual configurations, and the spermatozoa housed in the Fallopian tube of recently mated females are located as free cells within specialized crypts distributed, depending on the species of shrew, in the isthmus or ampulla. The ball-like soricid cumulus oophorus is matrix-free, and so is unusually dense at ovulation. This highly circumscribed structure remains as such for about $14 \mathrm{~h}$ until its loss in crocidurine shrews but, in soricine shrews, the cumulus mucifies and expands some hours after ovulation as a result of cumulus matrix secretion while in the oviduct. Experiments involving in vitro fertilization in the presence and absence of cumulus, and the observation of the fate of the acrosome within the cumulus indicate that, unlike the cumulus of most mammals, the shrew cumulus is responsible for induction of the 
acrosome reaction and has an essential role in the fertilization process (Bedford et al., 1997a,b).

We have turned to other Insectivora to obtain a better idea of the ubiquity and the significance of these unusual reproductive traits. Moles are the most closely related species to the Soricidae, and two species of American mole prove to have many, if not all, of the unusual reproductive features exhibited by shrews (Bedford et al., 1999). The present study examined various reproductive features in Atelerix albiventris, the African pygmy hedgehog with the aim of obtaining further perspectives on gamete function in the Insectivora.

Hedgehogs appear to be less closely related to shrews than are moles and, athough they are prominent within the Insectivora, much less is known about their reproduction. The European hedgehog is non-scrotal, with the testes lying in the posterior abdomen (Fowler and Racey, 1987), and the tail of the spermatozoon is inserted asymmetrically on the sperm head (Tripepi et al., 1982; Phillips and Dryden, 1991). The European hedgehog appears to be promiscuous (Reeve, 1986), male LH values are highest between February and April (El Omari et al., 1989), and females are fertile from about April to October (Deanesly, 1934; Morris, 1966), with photoperiod as the main factor regulating the seasonality of this hibernating mammal (Fowler, 1988). Deanesly (1934) has documented histological changes occurring in the female tract throughout the year. By contrast, the present subject, Atelerix, is sexually active throughout the year (Gregory, 1975), and breeds readily in captivity (Brodie et al., 1982).

\section{Materials and Methods}

Two males and six females obtained at about 6 weeks of age were maintained individually until sexual maturity and later, for between 4-5 months, at Kirksville College of Osteopathic Medicine. In addition, one mature male and one post-parturient female were purchased. The animals were provided with water and Laboratory Feline Diet number 5003 (PMI - Nutrition International Inc., St. Louis, MO) ad libitum, supplemented with mealworms (Tenebrio sp.) daily. The Kirksville College of Osteopathic Medicine animal care and use programmes are fully accredited by the American Association for the Accreditation of Laboratory Animal Care, International. All aspects of the study received full Institutional Animal Care and Use Committee (IACUC) approval, and were conducted in accordance with the Animal Welfare Act and the Guide for the Care and Use of Laboratory Animals.

\section{Male}

Each male hedgehog was killed using $\mathrm{CO}_{2}$. The penis was extruded and photographed, and the abdominal testes and epididymides were removed. Spermatozoa were released from one side of the tract by fine mincing of the caput, corpus and cauda epididymides, respectively, at $37^{\circ} \mathrm{C}$ into Dulbecco's modified Eagle's medium (DMEM) containing $10 \%$ fetal calf serum (FCS). Their morphology was studied in a phase-contrast microscope, and sperm counts were made with an Improved Neubauer haemocytometer on aliquots immobilized by dilution in water. For examination of sperm ultrastructure, small pieces of cauda epididymidis from the contra-lateral side of the tract were fixed in $2 \%$ glutaraldehyde in 0.1 mol cacodylate buffer $1^{-1}$, post-fixed in aqueous $1 \%(\mathrm{w} / \mathrm{v})$ osmium:1.5\% $(\mathrm{w} / \mathrm{v})$ potassium ferricyanide, dehydrated in alcohols, in propylene oxide or acetone, and embedded in Polybed 812 (Polysciences, Warrington, PA).

For analysis of the acrosomal matrix, a suspension of spermatozoa of known concentration from the cauda epididymidis was centrifuged at $100 \mathrm{~g}$ for $5 \mathrm{~min}$, then resuspended in Tris saline inhibitor solution (TNI) (150 mmol $\mathrm{NaCl} \mathrm{l}^{-1}, 25 \mathrm{mmol}$ Tris- $\mathrm{HCl} \mathrm{1} 1^{-1}, \mathrm{pH} 7.5,2 \mathrm{mmol}$ benzamidine $\mathrm{l}^{-1}, 1 \mu \mathrm{g}$ pepstatin $\mathrm{ml}^{-1}$ and $1 \mu \mathrm{m}$ leupeptin $\mathrm{ml}^{-1}$ ). The protein concentration of whole spermatozoa was determined using the method of Bradford (1976). For western blotting, aliquots of the sperm suspension were solubilized at $95^{\circ} \mathrm{C}$ for 3-5 min in SDS-dithiothreitol (DTT), and were then run on 12\% SDS-PAGE (Laemmli, 1970). Polypeptides were transferred to polyvinylidene fluoride (PVDF) membranes (Towbin and Gordon, 1984), which were then incubated in a blocking solution of PBS $(150 \mathrm{mmol} \mathrm{NaCl}$ $\left.\mathrm{l}^{-1}, 20 \mathrm{mmol} \mathrm{Na}_{2} \mathrm{PO}_{4} \mathrm{l}^{-1}, \mathrm{pH} 7.6\right)$ containing $0.1 \%(\mathrm{w} / \mathrm{v})$ Tween $20,5 \%$ goat serum, $5 \%(\mathrm{w} / \mathrm{v})$ nonfat dry milk and $2.5 \%$ BSA. Membranes were then incubated in primary serum diluted in PBS containing 1\% goat serum (PBS-GS). The two antisera used were prepared against a $32 \mathrm{kDa}$ polypeptide of bovine acrosomal matrix (Olson et al., 1997) and a $22 \mathrm{kDa}$ polypeptide of hamster acrosomal matrix (Olson et al., 1998), respectively. Both antisera recognize the same sets of homologous polypeptides in each species. Parallel control blots were exposed to pre-immune or non-immune serum. After three rinses in PBS-GS, the blots were incubated with an affinity-purified peroxidase-conjugated secondary antibody (Jackson ImmunoResearch, Park Grove, PA) and, after further rinses, immunoreactive bands were identified by enhanced chemiluminescence.

Whole spermatozoa of Atelerix albiventris were immunostained using bovine and hamster acrosomal matrix antisera (Olson et al.,1997; 1998), according to one of two different regimens. Spermatozoa were suspended in $0.1 \%(\mathrm{w} / \mathrm{v})$ Triton $\mathrm{X}-100 \mathrm{in}$ TNI for $30 \mathrm{~min}$ at $4^{\circ} \mathrm{C}$, or were fixed first for $30 \mathrm{~min}$ in $4 \%$ formaldehyde in $0.1 \mathrm{~mol} \mathrm{Na}_{2} \mathrm{PO}_{4}$ buffer $\mathrm{l}^{-1}$ and then permeabilized for $30 \mathrm{~min}$ in fixative containing $0.25 \%(\mathrm{w} / \mathrm{v})$ Triton X-100. Spermatozoa attached to poly-L-lysine-coated coverslips were incubated for $10 \mathrm{~min}$ at $-20^{\circ} \mathrm{C}$ in acetone, air dried, and incubated in a blocking solution of $5 \%$ donkey serum and 2.5\% BSA in Tris-saline (TN) $\left(150 \mathrm{mmol} \mathrm{NaCl}{ }^{-1}\right.$, $25 \mathrm{mmol}$ Tris- $\mathrm{HCl} \mathrm{l}^{-1}, \mathrm{pH} 8.0$, and $0.05 \%$ (w/v) Tween 20), before exposure to immune serum or to an equivalent dilution of preimmune serum in blocking solution. After three rinses in Tris saline (TN) with $1 \%$ donkey serum, the spermatozoa on coverslips were incubated in indocarbocyanine (Cy3)-conjugated, affinity-purified secondary antibody (Jackson ImmunoResearch) diluted in blocking solution. Finally, after several rinsings of the coverslips in $\mathrm{TN}$, the spermatozoa were examined by phase-contrast and epifluorescence microscopy. 


\section{Female}

Each female hedgehog was given 500 iu hCG i.p. On the next day, females were killed using $\mathrm{CO}_{2}$ at times ranging from 14.25 to $24.5 \mathrm{~h}$ after hCG. After removal of the reproductive tract, the fat-impregnated ovarian bursa was carefully peeled back to reveal the ovary, which was examined under a dissecting microscope for evidence of stimulated follicles or ovulation stigmata. The ovaries and Fallopian tubes were carefully dissected free of the mesovarian and mesosalpingeal fat, respectively. Cumuli removed from the ovarian surface and three cumuli recovered from the oviduct were exposed to solutions of $0.5 \%(\mathrm{w} / \mathrm{v})$ hyaluronidase (bovine type IV; ovine type V: Sigma, St Louis, MO) in medium 199 (M199) with Earle's salts (GIBCO BRL, Grand island, NY). Some eggs recovered within cumulus from non-ovulated follicles, and ovulated eggs extruded from the Fallopian tube, were fixed in acetic alcohol and stained in $0.75 \%(\mathrm{w} / \mathrm{v})$ lacmoid in $45 \%$ acetic acid. In addition, whole ovaries, isolated ovulating follicles with adherent cumulus, and oviducts were either fixed in $10 \%$ formalin and embedded in paraffin wax, or in $6.25 \%$ glutaraldehyde in cacodylate buffer, with later dehydration in alcohols and propylene oxide, and embedded in Polybed 812.

\section{Results}

\section{Male}

When extruded from the investing prepuce, the glans of the hedgehog penis appeared somewhat like a snail's head, by virtue of lateral 'horns' situated on either side of the external meatus (Fig. 1). The testes were located within the lower abdomen in para-anal recesses, and, as in other mammals with this arrangement, the cauda epididymidis protruded beyond the posterior border of the testis to lie in a shallow cremaster sac. For any one male, $60-71 \%$ of the extra-testicular spermatozoa were located in the cauda and vas deferens (Table 1). Spermatozoa released from the cauda into DMEM + FCS at $37^{\circ} \mathrm{C}$ showed a vigorous progressive motility with a slightly bent position of the head. As in European hedgehogs (Tripepi et al., 1982; Phillips and Dryden, 1991), Atelerix spermatozoa were characterized by a lateral position of the implantation fossa and so by an asymmetrical insertion of the tail on the head (Fig. 2). The rostrum of the acrosome was distinctly elongated beyond the nucleus and, within the acrosome, the perforatorium displayed barbs on each side, extending bilaterally in the flat plane of the sperm head. In parasagittal sections, the barbed nature of the perforatorium is reflected in the interrupted form of the extension that constitutes it (Fig. 3), and is shown directly if faintly in sections of the sperm head cut in the flat plane (Fig. 4).

Immunostaining of whole spermatozoa and immunoblotting of acrosomal extracts demonstrated the presence of a matrix component in the hedgehog acrosome common to that in the acrosome matrices of both hamsters and bulls (compare Fig. 5a with 5b). Specific immunostaining of the hedgehog acrosome was obtained with both the anti-

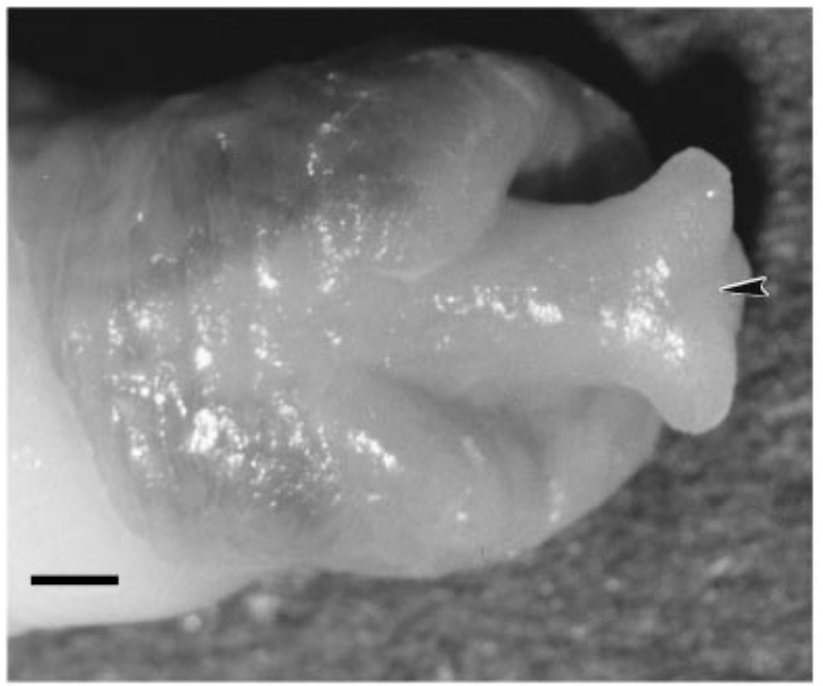

Fig. 1. Glans of the penis of the African hedgehog, Atelerix albiventris, extruded from the prepuce. The penis has a smooth surface devoid of the spines that are seen in many shrews and moles. The arrowhead denotes the position of the external meatus. Scale bar represents $1.25 \mathrm{~mm}$.

hamster (Fig. 5b) and anti-bovine acrosome matrix antibody. However, in contrast to the complex of matrix polypeptides seen in hamster and bull acrosomes, an immunoblot of the hedgehog sperm extract using anti-hamster acrosomal matrix antibody showed only two reactive bands, at about 29 and $14 \mathrm{kDa}$ (Fig. 6). When control serum was used, there was neither immunostaining nor any reaction with the bands on the immunoblots.

\section{Female}

The adult females weighed between 314 and $447 \mathrm{~g}$ (mean $382 \mathrm{~g}$ ) at about 5-6 months of age. The uterine segment was bicornuate, joining immediately above a single muscular cervix. The Fallopian tube emerged terminally from the side rather than from the extreme tip of the uterine horn, and extended back along the horn partially embedded in a fatty mesosalpinx, which was continuous with an equally fatimpregnated ovarian bursa.

The Fallopian tube was extremely short for the size of the animal, extending for only about $7.5 \mathrm{~mm}$ when dissected free of mesosalpinx, and its width was essentially uniform throughout the isthmus and ampulla until the terminal folds of the fimbria. Thus, the ovarian half of the oviduct was narrow compared with the greater width in many higher mammals that justifies the term ampulla (meaning 'swollen vessel'). The short isthmus was distinguishable from the ampulla only by virtue of a somewhat greater investment of smooth muscle and an epithelium with marginally fewer luminal folds. In addition, in no region did the hedgehog oviduct display the differentiated crypts that come to house spermatozoa and variously decorate the isthmus and or ampulla in shrews, depending on the species, and the ampulla in moles. The one postparturient female had mated 
Table 1. Numbers of spermatozoa in the male tract of the African pygmy hedgehog, Atelerix albiventris

\begin{tabular}{lccccc}
\hline & & \multicolumn{4}{c}{ Number of spermatozoa $\left(\times 10^{6}\right)$} \\
\cline { 3 - 5 } $\begin{array}{l}\text { Body weight } \\
(\mathrm{g})\end{array}$ & $\begin{array}{c}\text { Testis mass } \\
(\mathrm{g})\end{array}$ & $\begin{array}{c}\text { Caput } \\
\text { epidydimidis }\end{array}$ & $\begin{array}{c}\text { Corpus } \\
\text { epidydimidis }\end{array}$ & $\begin{array}{c}\text { Cauda } \\
\text { epidydimidis }\end{array}$ & $\begin{array}{c}\text { Vas } \\
\text { deferens }\end{array}$ \\
\hline 376 & 1.03 & 16.9 & 17.5 & 68.8 & 12.5 \\
403 & 1.05 & 38.5 & 28.0 & 80.8 & 16.0 \\
291 & 1.23 & 28.8 & 26.5 & 85.8 & 10.1 \\
\hline
\end{tabular}

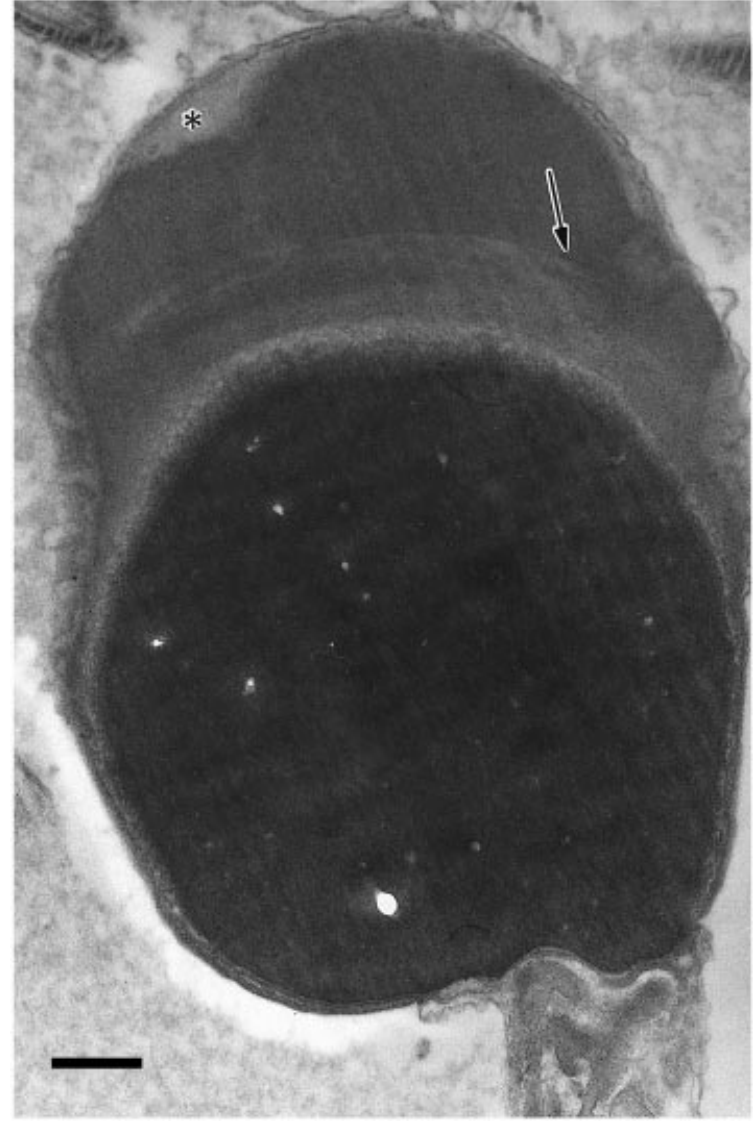

Fig. 2. Transmission electron micrograph of a section through the sperm head of Atelerix albiventris in the flat plane. The tail is inserted eccentrically at the posterior border of the nucleus. As in other Insectivora, the acrosome extends to a significant degree beyond the nucleus and the matrix is distinguished by a region of minimal electron density $\left(^{*}\right)$ that extends as a band over the anterior border (see Fig. 3). The perforatorium is not distinguished clearly within the acrosome in this example, but at least one barb of the perforatorium (arrow) can be seen faintly. Scale bar represents $0.47 \mu \mathrm{m}$.

after being housed overnight with a male, and flushing of the uterine cornua with $2 \mathrm{ml}$ warm DMEM at 10:15 h, resulted in the recovery of approximately $2 \times 10^{6}$ vigorous progressively motile spermatozoa from each horn. Attempts to dissect out the oviducts from the fat-impregnated mesosalpinx in this mated female were unsuccessful.

The ovarian surface, revealed only by incising and peeling back the fat-impregnated ovarian bursa, was characterized

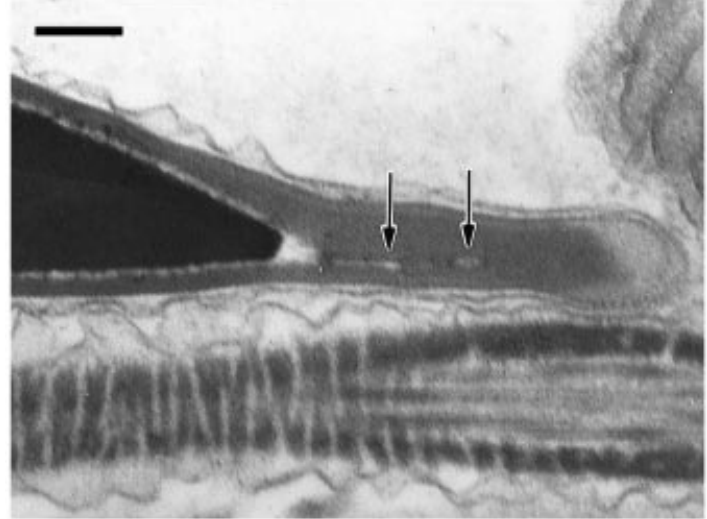

Fig. 3. Parasagittal transmission electron micrograph section through the rostral extension of the acrosome of Atelerix albiventris. The interrupted form of the perforatorium (arrows) reflects the fact that this lateral section passes through a perforatorium barb. The acrosomal matrix over the anterior border again reveals an unusual minimal density. Scale bar represents $0.22 \mu \mathrm{m}$.

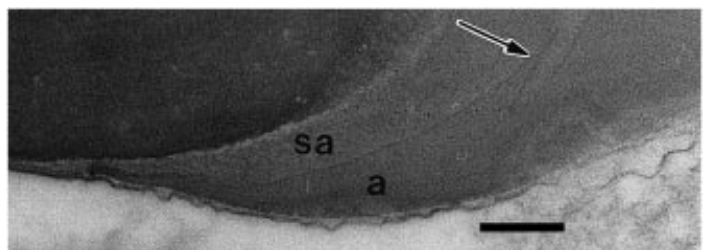

Fig. 4. Transmission electron micrograph of a section through one side of the sperm head of Atelerix albiventris in the flat plane. This reveals one of the lateral barbs (arrow) that extend from the perforatorium. a: acrosomal content; sa: subacrosomal material. Scale bar represents $0.40 \mu \mathrm{m}$.

by protruding haemorrhagic follicles in all of five animals killed between 14.5 and $24.25 \mathrm{~h}$ after hCG. In one animal, eggs recovered from several prominent follicles $14.5 \mathrm{~h}$ after hCG had reached metaphase II but, in this and one other female killed at $17 \mathrm{~h}$ after hCG, no follicles had yet ruptured. By contrast, all of the three remaining females had ovulated when killed 23.00-24.25 h after hCG. Ova ovulated by that time (3-4 per ovary) often remained tenaciously adherent to the ovarian surface within a relatively dense viscous cumulus (Fig. 7). Neither the cumulus oophorus adherent to the ovarian surface nor any of three cumuli collected from the upper oviduct showed any dispersal on exposure for about $10 \mathrm{~min}$ to solutions of $0.5 \%(\mathrm{w} / \mathrm{v})$ ovine and then 

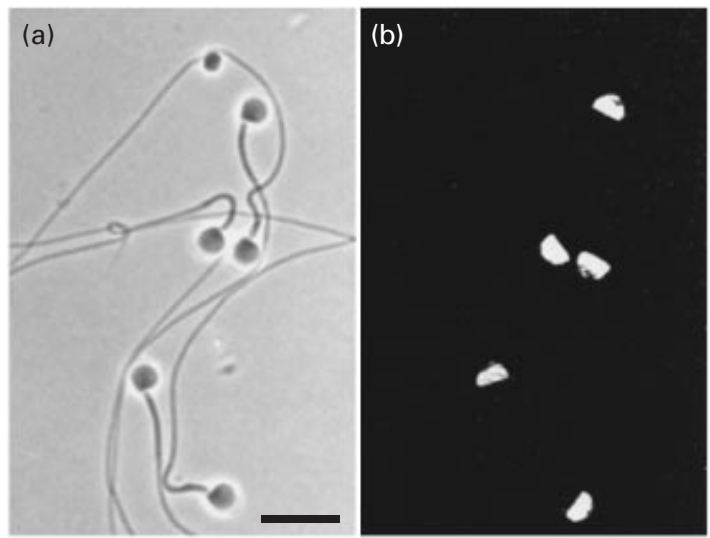

Fig. 5. Matched (a) phase-contrast and (b) fluorescence photomicrograph images of African hedgehog, Atelerix albiventris, spermatozoa suspended in $0.1 \%(\mathrm{w} / \mathrm{v})$ Triton X-100 and stained with antiserum prepared against hamster sperm $22 \mathrm{kDa}$ acrosomal matrix polypeptide. Spermatozoa show intense fluorescence over the anterior acrosome whereas the postacrosomal segment and flagellum are negative. The uppermost spermatozoon is unstained, has a smaller head image, and presumably had lost the acrosome. Scale bar represents $10 \mu \mathrm{m}$

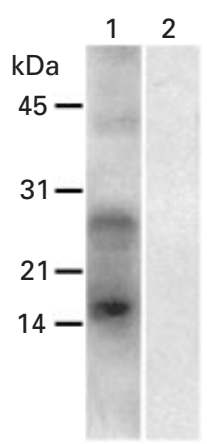

Fig. 6. Immunoblot analyses of total lysates of cauda epididymal spermatozoa of Atelerix albiventris. Each lane was loaded with $45 \mu \mathrm{g}$ of sperm protein. Lane 1 was immunostained using a 1:1000 dilution of an antiserum to a $22 \mathrm{kDa}$ hamster acrosomal matrix protein (AM22) which recognizes a family of antigenically related hamster acrosomal polypeptides, and lane 2 was stained with an identical dilution of preimmune serum. The immune serum reacted with two bands of 29 and $22 \mathrm{kDa}$ (lane 1), whereas the nonimmune serum displayed no immunoreactive bands (lane 2).

bovine hyaluronidase at room temperature, or at $37^{\circ} \mathrm{C}$. As a correlate, sections of resin-embedded glutaraldehyde-fixed ovulating follicles (Fig. 8) revealed a relative lack of matrix material in the interstices of the freshly ovulated hedgehog cumulus. In keeping with this finding, recently ovulated eggs extruded from one oviduct were also invested by equally dense cumulus (Fig. 9). However, chance sections through other eggs still resident in the upper region of another oviduct revealed a much more diffuse state of the cumulus, indicating the possibility of post-ovulatory cumulus mucification (compare with the least shrew, Cryptotis parva; Bedford et al., 1997a).

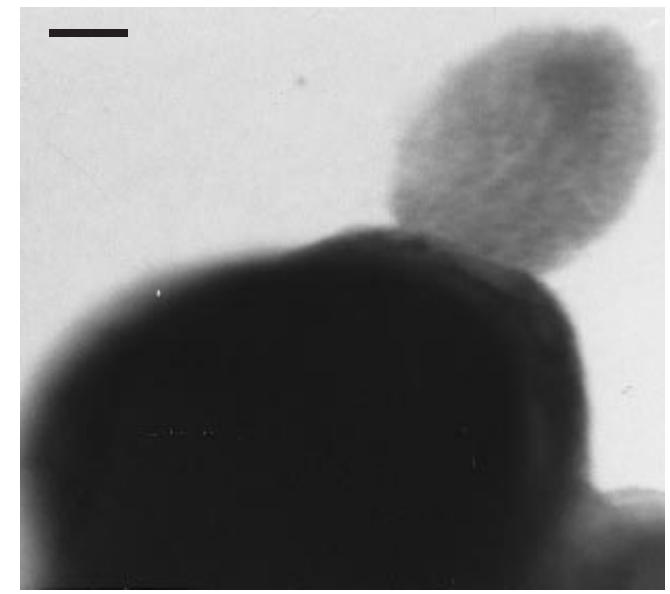

Fig. 7. An ovulating follicle of Atelerix albiventris seen under a dissecting microscope. The cumulus-oocyte complex has a circumscribed discrete appearance, with the region occupied by the oocyte and surrounding corona cells appearing as a small region of greater density. Scale bar represents $165 \mu \mathrm{m}$.

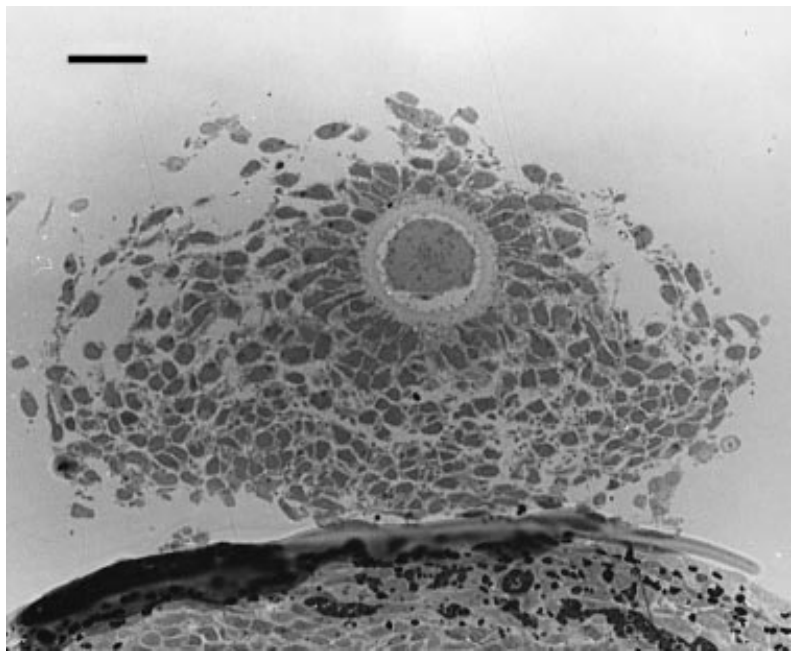

Fig. 8. Section through the surface of an ovulating follicle and cumulus-oocyte complex of Atelerix albiventris embedded in Polybed 812 plastic, and stained with toluidine blue. Note the apparent lack of matrix between the cumulus cells. The ovulation stigma lies out of the plane of section. Scale bar represents $55 \mu \mathrm{m}$.

\section{Discussion}

In keeping, perhaps, with the somewhat arbitrary constitution of the order, our study of the African hedgehog confirms that no one particular trait of the gametes or of the male or female reproductive tracts is restricted to and common to all Insectivora. One or two features that might seem to be characteristic of the Insectivora (for example, the barbed perforatorium on the sperm head), are not exclusive in that regard and occur also in a few families of other orders. Moreover, while some of the unusual traits in this respect that are seen in shrews and moles also occur in this 


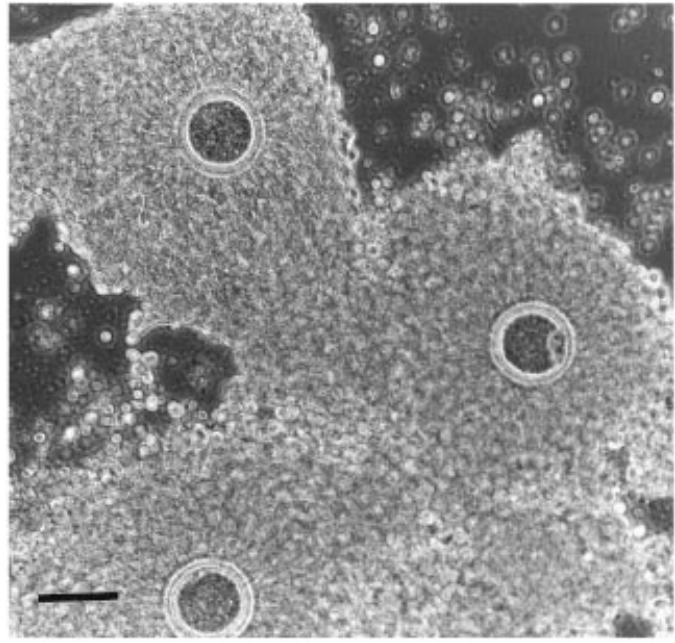

Fig. 9. Three cumulus-oocyte complexes slightly flattened beneath a cover slip, after being flushed from the upper Fallopian tube soon after ovulation, about $25 \mathrm{~h}$ after hCG injection. Although the complexes do not remain in the oviduct as discrete separate units, as do those of shrews, the cumulus is nevertheless unusually compact and its perimeter is relatively circumscribed. Scale bar represents $105 \mu \mathrm{m}$.

hedgehog, there are others (for example, sperm crypts in the oviduct) that do not.

In the males of all three insectivore families considered here, the testis and epididymis occupy a non-scrotal inguinal or low pelvic position within the abdomen, but this is a common arrangement in some other mammalian groups. In terms of sperm production and sperm numbers stored in the epididymis as a function of testis mass or body weight, shrews (and Suncus especially) occupy the low end of the spectrum with moles at the high end, and the hedgehog as represented by Atelerix, falling somewhere in between. Therefore, this hierarchy of sperm numbers appears to bear no direct relationship to any special feature of the female tract, particularly the occurrence of the sperm crypts in the oviduct that are evident in moles on the one hand, and shrews on the other (see below).

Penis morphology is highly variable also. The 'horned' glans of the hedgehog differs from the simple barrel-shaped spiny penis of moles, and from that in shrews, which varies from the blunt spine-covered organ seen in crocidurines to the spine-free penis in soricine shrews. Moreover, in soricine shrews, the penis can be vermiform in a way that may favour intra-uterine insemination (for example, in Blarina brevicauda; Sorex araneus or $S$. cinereus) or blunt at the tip (for example in Cryptotis parva and Sorex palustris). Further extreme variations in the form of the penis among insectivores include the very short stubby form seen in chrysochlorids (Dobson, 1882; J. M. Bedford and R. T. F. Bernard, unpublished) and the extremely long thin vermiform glans that typifies many of the Tenrecidae (Dobson, 1882).

As in the European hedgehog (Tripepi et al., 1982; Phillips and Dryden, 1991), the spermatozoa of Atelerix are distinguished by an asymmetric insertion of the tail on the sperm head. Such an asymmetry has not been observed in any other insectivores, and its significance is unclear. This form is not unique to hedgehogs, being evident for example in the spermatozoa of the free-tailed bat, Molossus ater (Bedford and Hoskins, 1990), of a Malaysian rodent, Pithecheir parvus (Breed and Yong, 1986) and, together with a balancing contralateral posterior extension of the head, in a South American rodent, Ctenomys (Feito and Gallardo, 1982). However, this asymmetry did not result in any unusual form of movement in hedgehog spermatozoa released from the epididymis or from the uterus, other than a slight bend of the head during their vigorous directed forward motility.

A second unusual characteristic displayed by hedgehog spermatozoa, but in company with the spermatozoa of all other insectivores studied, is a perforatorium with lateral barbs. Nothing is known at present about the way that hedgehog spermatozoa interact with eggs. However, in the case of some shrews at least, the acrosome reacts and is shed within the cumulus, and it is likely that the barbs enable the sperm head to attach, 'velcro-fashion', to the zona pellucida in the absence of the acrosome (Bedford et al., 1997b; Bedford, 1999). In most mammals, stabilization of the reacted acrosome during binding to the zona pellucida in the preliminaries to penetration may be effected by the acrosome matrix that is clearly evident under the electron microscope. It is therefore of related interest that, as in moles (Bedford et al.,1999), and shrews (G. E. Olson, V. P. Winfrey, S. K. Nagdas, O. B. Mock and J. M. Bedford, unpublished), the hedgehog acrosomal matrix is relatively simple, comprising only two peptides rather than the more numerous complex of peptides seen in higher mammals, such as hamsters and cattle.

Although an extended acrosomal rostrum and the barbed perforatorium typify all the other insectivores examined thus far, it must be emphasized again that neither of these features are confined to the Insectivora per se. A comparable rostral elongation of the acrosome occurs in some microbats and prosimian primates, for example, although without a barbed form to the perforatorium, while other non-insectivores as diverse as elephant shrews (Woodall,1991), and flying foxes (megabats) (Rouse and Robson, 1986; Cummins et al., 1988) display both an elongate acrosome and a barbed perforatorium. Finally, although the rostrum of the acrosome is very modest in canids, nevertheless it covers a perforatorium with a distinctly barbed configuration (J. M. Bedford, unpublished).

As noted, in the case of shrews, the barbed form of the perforatorium seems to be linked to a situation in which the acrosome is induced to react within the cumulus oophorus rather than by the zona pellucida, with the barbs probably providing the means for attachment of the reacted sperm head to the zona surface. However, the cumulus of the hedgehog differs somewhat from that of shrews. The hedgehog cumulus does not have quite the same discrete ball-like form that is shed freely from the shrew follicle, and first adheres tenaciously to the stigma for some time after follicular rupture. Nonetheless, compared with the matrixrich, more diffuse cumulus typical of most higher mammals, that of the hedgehog is compact, has very little matrix, and is evidently resistant to hyaluronidase in the freshly ovulated state. The mole cumulus appears rather similar, although some portion of it is dissociated by hyaluronidase (Bedford et 
al., 1999). Thus, it would be of great interest to know whether the cumulus of hedgehogs (and moles) has the critical role for fertilization that it seems to have in shrews, or whether, as in most higher mammals, their eggs can still be fertilized after the cumulus has been removed.

The dense nature of the hedgehog cumulus is of interest for other reasons. A survey of the situation in a variety of mammals has indicated that the particular character of the cumulus oophorus is linked to the form of the upper oviduct (Bedford, 1996). In marsupials, in which the eggs discard the cumulus before ovulation, the very narrow dimensions of the upper oviduct ensure a snug fit of the naked egg within it before the ascent of the fertilizing spermatozoon to that site. Conversely, in most eutherian mammals, in which the tiny egg is dwarfed by the dimensions of a very spacious ampulla, preovulatory mucification increases the size of the cumulus and so the target for spermatozoa, very significantly. Thus, preovulatory expansion may facilitate the ability of this egg-associated structure to act as a trap for the very small 'vanguard' population of spermatozoa that reaches the ampulla by the time of ovulation (Bedford, 1996). For example, the expanded cumulus of rats occupies most of the swollen ampulla, and has been observed to sequester the great majority, and sometimes all, of the few spermatozoa that reach it in the peri-fertilization period, thereby promoting early interaction between the gametes (Bedford and Kim, 1993). As has been observed here, in hedgehogs, the diameter of the oviduct ampulla is not spacious, hardly exceeding that of the isthmus, and as a correlate the cumulus is relatively compact, with minimal matrix evident in the interstices of the ovulated mass. Thus, the situation observed in the present study in hedgehogs further supports the possibility that the character or size of the cumulus, which in many species is regulated by pre-ovulatory mucification, tends to be directly correlated with the dimensions of the oviduct ampulla. The same conclusion holds true for moles (Bedford et al., 1999) and perhaps more so for shrews. Yet, even the compact cumulus in the shrew, Suncus, appears to act as a sperm sequestering agent to some extent (Bedford et al., 1997b), and this seems to be true also for the soricine, Cryptotis, during the peri-fertilization period. Subsequently, however, in Cryptotis, a delayed matrix secretion and expansion of the cumulus that occurs after ovulation within the oviduct seems rather to protect the fertilized egg from the hundreds of motile spermatozoa that become enmeshed within it after their release from neighbouring ampullary crypts (Bedford et al., 1997a).

In summarizing her histological study of the female reproductive cycle in wild-caught animals, Deanesly (1934) concluded that the European hedgehog, Erinaceus europeus, ovulates spontaneously. In the present study, however, Atelerix females ovulated several oocytes beginning at about $22 \mathrm{~h}$ after hCG adminstration. This responsiveness to hCG implies that this African hedgehog is an induced ovulator, as are shrews and moles, and calls for a further evaluation of the European hedgehog in this regard.

This study was supported by EPA grant CR823734010 (O. B. Mock), and NIH grant HD 20419 (G. E. Olson). The authors are indebted to Lee Cohen-Gould of the Electron Microscopy Unit of
Weill Medical College at Cornell University for her help with ultrastructural aspects, and to J. J. Rasweiler IV for photography of Fig. 8.

\section{References}

Bedford JM (1991) The co-evolution of mammalian gametes. In A Comparative Overview of Mammalian Fertilization pp 3-35 Eds BS Dunbar and MG O'Rand. Plenum Press, New York

Bedford JM (1996) What marsupial gametes disclose about gamete function in eutherian mammals Reproduction Fertility and Development 8 569-589

Bedford JM (1999) The implications of unusual sperm/female relationships in mammals. In The Male Gamete pp 81-92 Ed. C Gagnon. Cache River Press, Vienna, IL

Bedford JM and Hoskins DD (1990) The mammalian spermatozoon: morphology, biochemistry and physiology. In Marshall's Physiology of Reproduction, 4th Edn, Vol. 2 Reproduction in the Male pp 379-568 Ed. GE Lamming. Churchill Livingstone, London

Bedford JM and Kim HH (1993) Cumulus oophorus as a sperm sequestering device Journal of Experimental Zoology 265 321-328

Bedford JM, Cooper GW, Phillips DM and Dryden GL (1994) Distinctive features of the gametes and reproductive tracts of the Asian musk shrew, Suncus murinus. Biology of Reproduction 50 820-834

Bedford JM, Mock OB and Phillips DM (1997a) The unusual ampullary sperm crypts, and behavior and role of the cumulus oophorus in the oviduct of the least shrew, Cryptotis parva. Biology of Reproduction 56 1255-1267

Bedford JM, Mori T and Oda S (1997b) The unusual state of the cumulus oophorus and of sperm behavior within it, in the musk shrew, Suncus murinus. Journal of Reproduction and Fertility $110127-134$

Bedford JM, Mock OB, Nagdas SK, Winfrey VP and Olson GE (1999) Reproductive features of the eastern mole (Scalopus aquaticus) and star-nose mole (Condylura cristata) Journal of Reproduction and Fertility 117 345-353

Bradford MM (1976) A rapid and sensitive method for the quantitation of microgram quantities of protein utilizing the principle of protein-dye binding Analytical Biochemistry 72 248-254

Breed WG and Yong HS (1986) Sperm morphology of murid rodents from Malaysia and its possible phylogenetic significance American Museum Novitates 2856 1-12

Brodie ED III, Brodie ED, Jr and Johnson JA (1982) Breeding the African hedgehog Atelerix pruneri in captivity International Zoo Yearbook 22 195-197

Cummins JM, Robson SK and Rouse WG (1988) The acrosome reaction in spermatozoa of the grey-headed flying fox (Pteropus poliocephalus: Chiroptera) exposes barbed subacrosomal material Gamete Research 21 11-22

Deanesley R (1934) The reproductive processes of certain mammals VI. The reproductive cycle of the female hedgehog Philosophical Transactions of the Royal Society B 223 239-276

Dobson GE (1882) A Monograph of the Insectivora, Systematic and Anatomical J Van Voorst, London

El Omari B, Lacroix A and Saboureau M (1989) Daily and seasonal variations in plasma LH and testosterone concentrations in the adult male hedgehog (Erinaceus europaeus) Journal of Reproduction and Fertility 86 145-155

Feito R and Gallardo M (1982) Sperm morphology of the Chilean species of Ctenomys (Octodontidae) Journal of Mammalogy 63 658-661

Fowler PA (1988) Seasonal endocrine cycles in the European hedgehog, Erinaceus europaeus Journal of Reproduction and Fertility 84 259-272

Fowler PA and Racey PA (1987) Relationship between body and testis temperatures in the European hedgehog, Erinaceus europaeus, during hibernation and sexual reactivation Journal of Reproduction and Fertility $\mathbf{8 1}$ 567-573

Gregory M (1975) Observations on vocalisation in the central African hedgehog Erinaceus albiventris, including a courtship call Mammalia 39 1-7

Laemmli UK (1970) Cleavage of structural proteins during the assembly of the head of bacteriophage T4 Nature (London) 227 680-685

Morris B (1966) Breeding the European hedgehog Erinaceus europaeus in captivity International Zoo Yearbook 6 141-146

Olson GE, Winfrey VP, Neff JC, Lukas TJ and Nagdas SK (1997) An antigenically related polypeptide family is a major structural constituent of a stable acrosomal matrix assembly in bovine spermatozoa Biology of Reproduction 57 325-334

Olson GE, Winfrey VP and Nagdas SK (1998) Acrosome biogenesis in the 
hamster; ultrastructurally distinct matrix regions are assembled from a common precursor polypetide Biology of Reproduction 58 361-370

Phillips DM and Dryden GL (1991) Comparative morphology of mammalian gametes. In A Comparative Overview of Mammalian Fertilization pp 37-50 Eds BS Dunbar and MG O'Rand. Plenum Press, New York

Reeve NJ (1986) Mating strategy in the hedgehog (Erinaceus europaeus) Journal of Zoology London (A) 210 613-614

Rouse GW and Robson SK (1986) An ultrastructural study of megachiropteran (Mammalia:Chiroptera) spermatozoa: implications for chiropteran phylogeny Journal of Submicroscopic Cytology 18 137-152

Springer MS, Cleve GC, Madsen O, de Jong WW, Waddell VG, Amrine HM and Stanhope MJ (1997) Endemic African mammals shake the phylogenetic tree Nature (London) 388 61-64
Stanhope MJ, Waddell VG, Madsen O, de Jong WW, Hedges SB, Cleve GC, Kao D and Springer MS (1998) Molecular evidence for multiple origins of Insectivora and for a new order of endemic African insectivore mammals Proceedings National Academy of Sciences USA 95 9967-9972

Towbin H and Gordon J (1984) Immunoblotting and dot-immunoblotting current status and outlook Journal of Immunological Methods 72 313-340

Tripepi S, Saita A and Carelli A (1982) Ultrastructural peculiarities and movement of the spermatozoa of Erinaceus europaeus. Biology of the Cell 45 157

Woodall PF (1991) An ultrastructural study of the spermatozoa of elephant shrews (Mammalia: Macroscelidea) and its phylogenetic implications Journal of Submicroscopic Cytology 23 47-58 